Paideusis

\title{
Engaging Bodhisattva Compassion in Pedagogical Aporias
}

\section{Mei Hoyt}

Volume 21, numéro 2, 2014

\section{Working Compassion}

URI : https://id.erudit.org/iderudit/1071563ar

DOI : https://doi.org/10.7202/1071563ar

Aller au sommaire du numéro

Éditeur(s)

Canadian Philosophy of Education Society

ISSN

0838-4517 (imprimé)

1916-0348 (numérique)

Découvrir la revue

Citer cet article

Hoyt, M. (2014). Engaging Bodhisattva Compassion in Pedagogical Aporias. Paideusis, 21(2), 24-31. https://doi.org/10.7202/1071563ar

\section{Résumé de l'article}

In teaching culturally sensitive and difficult issues, tensions and interruptions may arise, and educators and students may retreat to their respective comfort zones to avoid conflict and suffering, a pedagogical aporia occurs. This article introduces and examines Bodhisattva compassion from the Buddhist tradition, which offers insights and wisdom in transforming unexamined emotional responses into healthy and nonviolent expressions and embodiment of difference and dissonance. By tracing the Chinese etymological history of the term compassion and its use in Buddhist literature, I argue that Bodhisattva compassion embodies 悲心, a somatic, but unattached and awakened responsive heartmind. Bodhisattva compassion recognizes and accepts the unavoidability of human suffering, but it also liberates us from the common assumption of fellow-feeling and pity subsumed in sorrow and suffering. Guided by the concepts of wisdom and transforming the mind in Buddhism, bodhisattva compassion focuses on lucid awareness of one's responsive heartmind and skillful actions to engage suffering. Pedagogy enlightened by bodhisattva compassion has curricular and instructional implications. In the struggle of identity politics or for social justice, it is probably more critical to develop ethical and undifferentiated compassion pedagogy than wrestling with power dynamics in our teaching.
(C) Mei Hoyt, 2014

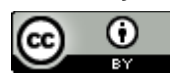

Ce document est protégé par la loi sur le droit d'auteur. L’utilisation des services d'Érudit (y compris la reproduction) est assujettie à sa politique d'utilisation que vous pouvez consulter en ligne.

https://apropos.erudit.org/fr/usagers/politique-dutilisation/ 


\title{
Engaging Bodhisattva Compassion in Pedagogical Aporias
}

\author{
MEI HOY'T \\ University of North Texas
}

In teaching culturally sensitive and difficult issues, tensions and interruptions may arise, and educators and students may retreat to their respective comfort zones to avoid conflict and suffering, a pedagogical aporia occurs. This article introduces and examines Bodhisattva compassion from the Buddhist tradition, which offers insights and wisdom in transforming unexamined emotional responses into bealthy and nonviolent expressions and embodiment of difference and dissonance. By tracing the Chinese etymological history of the term compassion and its use in Buddhist literature, I argue that Bodhisattva compassion embodies 悲心, a somatic, but unattached and awakened responsive heartmind. Bodhisattva compassion recognizes and accepts the unavoidability of human suffering, but it also liberates us from the common assumption of fellow-feeling and pity subsumed in sorrow and suffering. Guided by the concepts of wisdom and transforming the mind in Buddhism, bodhisattva compassion focuses on lucid awareness of one's responsive heartmind and skillful actions to engage suffering. Pedagogy enlightened by bodhisattva compassion has curricular and instructional implications. In the struggle of identity politics or for social justice, it is probably more critical to develop etbical and undifferentiated compassion pedagogy than wrestling with power dynamics in our teaching.

\section{Introduction}

In teaching culturally sensitive courses in teacher education, educators who address controversial, critical, and difficult issues often encounter silence, resistance, or anger from students in classroom. At times when tension arises, it is impossible to teach the curriculum we prepare to teach or exercise the pedagogy we plan to use. When such disruptions take place, communications may shut down and both educators and students may retreat to their respective comfort zones to avoid conflict and suffering; a pedagogical impasse may occur.

While I acknowledge that critical curriculum scholars may not follow Ralph Tyler's (1949) traditional instructional planning model comprised of learning objectives, learning experiences, evaluation methodology, and so on, there are still some sort of "goals" to accomplish in each lesson of each course. For example, we may want to emphasize learning in ways favorable to social justice and equity. My point here, however, is not that we should teach social justice, diversity, and equity per se, rather, I would argue that how we define and approach these issues of diversity and difference as they arise in the classroom dynamics become an important curricular opportunity, and through engaging with it, we can accomplish an important curricular goal - student learning.

In this article I first address our embodied and emotional responses to difference, and then explicate the concept and practice of compassion in Buddhism. Next, I explore the notion of aporia of Derrida,

(C) Copyright 2014. The author, Mei Hoyt, assigns to Paideusis the right of first publication and educational and non-profit institutions a non-exclusive license to use this document for personal use and in courses of instruction provided that the article is used in full and this copyright statement is reproduced. Any other usage is probibited without the express permission of the author. 
especially the aporia in teaching as discussed in Hongyu Wang's (2005) work. Last, I introduce my own pedagogical practice using Bodhisattva compassion in educational aporias.

\section{Encountering Emotional and Embodied Responses and Differences}

In teaching courses focusing on multiculturalism, diversity or social justice topics, instructors most likely will encounter resistance, anger, and silence when the content collides with students' established cultural, social or religious views, assumptions and beliefs. The sensitive topics and the demand for social justice of the nature of those courses at times encounter aporias, a Derridean notion that Hongyu Wang (2005) delicately explicates as the poetic possibility of the impossible in multicultural education. Beyond poetic encountering, I suggest we also need to look at students' embodied and emotional responses in pedagogical aporias that may hinder or assist the process of learning. Emotional responses are so human, natural, and important that we should not evade them. Moreover, we must note that before someone is emotional, a feeling has developed, since "feelings precede the development of our emotions" (Dupont, 1994, p. 6). Feelings and emotions are important for developing and maintaining intrapersonal, interpersonal, and social equilibrium (Piaget, 1981). Evading emotions fails to recognize and acknowledge our students' authentic engagement with learning. Further, their development and growth would be obstructed, if emotions were evaded.

Novella Keith (2010) discusses how a pedagogy of difference brings hidden emotions into view. In such a pedagogy, fear, needs, and emotions are expressed in healthy and nonviolent ways, and we are invited to an opportunity to deconstruct the binary compositions of self and other, right or wrong. As a result, a pedagogy engaging difference and emotions brings about self-other transformations and deep human connectedness. Embodiment is what we experience from inside: our feelings, emotions, sensations that constitute the fabric of our lives (Hayles, 2002). Embodied responses are beyond being emotional, varying from emotional, sensational, to proprioceptive. Embodiment is what is experienced here and now, and thus is different from, and cannot be achieved through reflections.

How do we transform unexamined emotional responses into healthy and nonviolent expressions and embodiment of beliefs, dissonance, and constructive engagement with the content, self, and others is critical for meaningful dialogues and social justice for all. Further, how do we help students to transform personal encountering into professional engagement? Emotional and embodied transformations require a deep knowing of ourselves, of the context we are in, and taking compassionate steps to work with embodied otherness or differences. Each person in the classroom has come to embody his or her experiences, beliefs, assumptions, and consciousness in the course of their lifetime. Engaging with differences will be a continuous process of unfolding their embodied life experiences. In this paper, I propose that such a process can be cultivated and supported by a pedagogy of compassion. In the next section, I will discuss Buddhist compassion and wisdom as an approach to cultivating deep connectedness, through, rather than avoidance of, emotions and feelings.

\section{Understanding Compassion in Buddhism}

The Buddhist's compassion is better understood when compared with its use in Western cultures. Yao (2008) explains Buddhism compassion is for all sentient beings, that is, a compassionate mind, heart, or body is not only for humans, but also for animals, insects, plants, and other creatures. Secondly, compassion is unconditional: our compassion toward others should not be limited to those one likes, agrees with, and admires. True compassion extends to all sentient beings, regardless of whether they are strangers, opponents, or even enemies, those whom one dislikes, disagrees with, or opposes (although when one reaches Buddhahood even such dislikes or oppositions do not matter or have no existence). Scholars have critiqued conditional compassion in the West. For example, drawing upon Martha Nussbaum, Claudia Eppert (2010) argues that compassion in the post 9/11 era was merely used as self/other dualism in that compassion is reserved for those in one's favor, those who share a cultural or religious common ground with self. Thirdly, there is no differentiation of the degrees of compassion: every compassionate thought, word, or act will be 
considered as compassion.

Marjorie Garber (2004) traces the etymological history of the term compassion in Western cultural tradition, pointing out the etymological meanings of compassion are "together" and "pity" which basically meant "suffering together with another, participation in suffering" and "fellow-feeling" (quoted in Eppert, 2010, p. 19). The understanding of "fellow-feeling" and "participation in suffering" is quite different from the Buddhist' understanding of compassion. Venerable Sujuva in his book Meditation on Loving Kindness and other Sublime States distinguished the differences between compassion and sorrow (suffering together with others). In Chinese, these two words are spelled as 悲心 and 悲伤. The first characters of the both terms are 悲. But the second terms are different: one is 心 (heart), and the other is 伤 (sorrow). The use of heart and sorrow has different indications. 悲心 (compassion) in Buddhism emphasizes the notion of heart, or embodied, concentrated and awakened "responsive heartmind" (Eppert, 2010) on the way toward enlightenment and cessation of suffering. 伤 (sorrow) - in traditional Chinese, 傷 - etymologically symbolizes a soldier who was hurt by an arrow, referring to a bodily and physical harm. Feeling sorrow for others is a natural response to others' pain or suffering. It may include the feeling of pity and grief toward others, and feeling the pain and suffering with others, which is similar to the "fellow-feeling" of the compassion in Garber's analysis. However, sorrow can paralyze our capacities to fully engage suffering toward the cessation of suffering. 悲心, or compassion, requires one to take further steps to acquire lucid awareness of what is going on in our own heart and to respond with "responsive heartmind."

The word 悲 is composed by two characters, 非 and 心. Together they mean that "it is not this heart," or "there is no heart." Some may find this meaning problematic since the literal meaning of this word indicates that one does not have a heart when expressing or practicing compassion. However, the Buddhist insights of compassion transcend both the etymological and literal interpretations of compassion, requiring one to ultimately eradicate self or developing no self and nonattachment to feelings or minds. Compassion as one of the four noble abodes of Buddhism (loving-kindness, compassion, sympathetic joy, and equanimity) ${ }^{1}$ is not innate in that it needs cultivation and skillfulness, and grows out of a calm mind and lucid awareness of the present. Compassion is a learned capacity to feel other's pain, sorrow, despair, or suffering, but at the same time is able to have lucid awareness of the causes of suffering and dependent originations of things. Buddhist compassion recognizes and accepts the unavoidability of human suffering and practices skillful actions so not to be drawn into the circle of sorrow. Developing an unattached compassion needs wisdom.

\section{Exercising Compassion with Wisdom}

Bodhisattva is a belief and practice embodied in Mahayana Buddhism, and the basic idea of Bodhisattva is that one could postpone or sacrifice one's own enlightenment in order to help other suffering beings. K. Sri Dhammananda (n.d) in his book What Buddhists Believe pointed out that "[a] Bodhisatta (Bodhisattva) is a being devoted to Enlightenment” (p. 21). However, such devotion to Enlightenment or Buddhahood motivates the enlightened one to indefinitely postpone one's own enlightenment because a Bodhisattva believes that lessening the suffering of others throughout his/her life is far more urgent and humanistic than achieving one's own enlightenment: "Bodhisattvas are future Buddhas who, out of compassion for their fellow human beings, have delayed their own attainment of Buddhahood until they have helped others towards liberation" (p. 59). Similarly, in Chinese culture, influenced by Buddhist tradition, a Bodhisattva is compassionate, present and available to those in need. For example, Kuan-yin is a Bodhisattva, a great perfected Bodhisattva, but not Buddha, and "[t]hey are perfect because, although they are qualified to become Buddhas, they choose to remain as Bodhisattvas, subject to endless rebirths, in order to save others" (Hamiltion, 1950, p. 148). So, Bodhisattvas are those who fully engage in the now-and-present in order to help those around them. Sri Dhammananda pointed out that a Bodhisattva needs compassion and wisdom to cultivate virtues, enlightenment, and perfection. Similarly, Fuchuan Yao (2008) explains that Bodhisattva

${ }^{1}$ Detailed discussion of the four noble abodes, please see Eppert (2010) Heartmind literacy: Compassionate imagining and the four Brahmaviharas. 
practice constitutes wisdom (prajna) and compassion (karuna), which are the foundation of Buddhist ethics.

As educators, we do not always have teachable moments; often we are encountered by "unteachable moments" (Wang, 2010) when learning and teaching seem to break down. Thus, engaging Bodhisattva ethics in teaching may provide us with new insights and practical ideas, and moreover would allow us to develop compassionate beings in pedagogical impasse or aporias.

Wisdom in Bodhisattva ethics is a joint effort of mind and body: it is not merely rational, analytical, intellectual, or logical capacities one obtains. A bodhisattva's wisdom includes letting go what comes to your mind and body at that moment, developing nonattachment capacities and transforming the mind. The notion of wisdom here is different from the common understanding of being smart, having knowledge about something, or having good judgment. The following observations from a Buddhist practitioner highlight the essence of wisdom: "Cultivating the heart not to be unsettled by the external environment, and transforming the environment to follow one's heartmind" (Heya, 2013, p. 189, my translation). The focus of wisdom is heartmind, of an emotional and cognitive being, which should be differentiated from an attached "I" or self. Heartmind in Buddhist tradition refers to the understanding that heart and mind are conjoined, thus including the qualities of emotion and affect (Eppert, 2010) in the quality of the mind. Without heart one loses soul and humanity, without mind one cannot fully develop mindfulness and wisdom. An engaged being with heartmind has the capacity to clearly observe the process of the mind's activity: what the mind is up to, what the mind was up to, and how the mind is turning to war, and so on, all the while without being attached to any of these. Developing Bodhisattva wisdom is very important for one to practice compassion in adversity, difficult situations, or suffering, including one's own.

Transforming one's mind is the key in Bodhisattva wisdom. Buddhist practices are mostly around the theme of mind, for example, mindfulness, and calming the mind. However, mind does not exist alone, our life is the coexistence of mind and matter, and mind is embodied mind (Clark, 2011), so it would not be realistic to examine mind without awareness of realities we encounter. The basic functions and aims of transforming the mind are to help the heart become calm and unattached. The process of transforming the mind includes transforming the vijnana to wisdom. Vijnana is usually understood as consciousness in English, but it is not exactly the consciousness that we normally think of. Drawing upon Sue Hamilton, Jiande Lin (2010) writes that vijnana is "consciousness of" something. He distinguishes the consciousness in our common understanding as having an assumption of something. For example, we have an understanding of what a tree looks like: its color, shape, size, and then we give (evaluative) meanings to the color, shape, or size. This way our consciousness of trees has existing meanings and is conditioned by our discernment or doctrines, which leads us to believe that things should be or function in a particular way according to our presumptions. However, "consciousness of" indicates that consciousness has a process, realizing that things become things but are not things in and of themselves. Thus, the foundation of transforming the mind is to transform consciousness to a lucid mindfulness of "consciousness of", a present without assumed entities and concepts, or even goals, without attaching to the previous insights or the future consciousness. Meanwhile, transforming the mind does not mean merely giving up. What is being given up is our attachment to our vijnana, obscured by self-centeredness and self-determination. From the practitioners' perspective, transforming the mind requires one to calm the mind first, usually cultivated by meditation, which is another important component of Bodhisattva practices, which I will not elaborate here. Nonattachment to our minds or consciousness needs us to clear out the illusion of self, from cultivating self to developing an enduring noself in practicing compassion.

\section{Self, No-self, and Compassion}

Transforming the mind is to transform a heartmind from attached self-centeredness to no-self. Clarence Hamilton (1950) explicates the intricacies of compassion in Mahayana Buddhism. He especially emphasizes the altruistic quality/character of Bodhisattva and underscores the core of no-self in compassion: "His thought of self drops away, and he loses the fears that go with self-seeking. Thus compassion becomes the moving power and directive factor of a new and higher life" (p. 149). What should be noted here is that, although in Buddhism it ultimately cultivates no-self and emptiness, the journey of a Bodhisattva is infused 
with self-perfection/cultivation, it is a dynamic interplay of self and no-self along the journey. No-self in Buddhism does not deny a temporary self, a "conventional self" (Inada, 2000), or a "nominal self" (King, 2006), and this self is constantly changing for the betterment of Bodhisattva ethics. The "no-self" in Buddhism means the "'emptiness' of self or no permanent essence of personhood" (Yao, 2008, p. 274). When we have difficulties to let something go, or we are attached to something and unable to transform the mind, most often this is because we have the strong conception of an existing self, our attachment to ideas, thoughts, and perceptions. An attachment to ideas, thoughts, or literature in our scholarship or teaching may lead us to pedagogical aporias even though we think we have the best to offer.

\section{Engaging Bodhisattva Ethics in Pedagogical Aporias}

\section{Aporias and Educational Aporias}

Aporia is usually understood as "the state of impasse, non-passage, or logical contradiction that can never be permanently resolved, a state of constant dilemma with no general or final solution" (Wang, 2005, p. 45). Pedagogical aporias arise from the borderlines along which we line up our conceptual, cultural, and disciplinary traditions, and it becomes difficult to cross over to the other side. Multicultural or diversity education is usually known as teaching social justice and social change for a better world, topics in a multicultural or diversity class involve issues of race/racism, sexism, classism, homophobia, xenophobia, and other forms of bias or hatred that can be very controversial and their discussion could be very difficult for some students. The emergence of an aporetic situation around controversial issues in multicultural education puts both the teacher and student into suffering: students encounter uncomfortable situations and difficult knowledge that may shake their foundational belief structure about society and others; and teachers have to respond to students' challenging emotional and embodied responses. When examining the difficult knowledge that is historically oppressed, displaced, or undemocratically practiced, there may come the dilemma of impossibility to teach - the pedagogical aporias.

However, it is the very aporia where Wang (2005) creatively unfolds the possibility of the impossibility of teaching - through a Derridean responsibility: "Any decision or responsibility guaranteed by predetermined rules or principles is merely a technical application instead of a responsible response." For Derrida, she continues, "responsibility is not grounded by any "proper center," or guaranteed by any mature technology, but is embedded in confronting the dilemmas of the human condition"(pp. 48-49). Further, Wang deconstructs the aporias created by our culture and society's dualism concerning center and margin, self and other, and intellect and emotion, in ways that do not find final solutions but by questioning the very existence of aporia. To be responsible, a teacher has to experience aporia himself or herself to be able to work through the tensions, with double gestures to devote oneself to the tradition (or the knowledge of social justice) and at the same time to see the promises of the new mode of subjectivities of both teacher and students. And the controversies and aporias must be lived through our journey of teaching, and

[1]iving with paradoxes in the spirit of affirmation, we must seek passage and such negotiation has to be creative, singular, and context-specific. This invention as an experience and experiment of aporia is "poetic, poetical"; it cannot be logically described, but has to be experienced, to be felt, and to be lived. (p. 51)

The poetic and felt aporia asks us to look beyond the mechanical and behavioral work of teaching and toward an embodied and lived pedagogical ethics. In my own teaching in multicultural education courses and culture and identity courses in college, I have experienced both aporetic moments and breakthroughs. There are times when I was stuck by the impossibility of teaching, feeling students' strong resistance to and questioning of my authority of teaching the "other" stories that confronts their "sedimented perceptors" (Slattery, 2006). Immersed in a general American culture with pragmatic ideals, many students seek to locate the "right" solutions and "best" or "effective" methods to teach diverse students, but they are reluctant to face historical ruins and injustice. Such courses are taken as an assemblage of celebrative things rather than 
reparation to historical injury and present injustice (Pinar, 2011). Taken as an instrument, a method, or a behavioral checklist, to teach means teaching toward something already known, ready-made, ideal, and letting others follow one's footsteps to the "right thing." Multiculturalism and diversity take reparation as their centrality, often provoking controversies and opening to complicated conversations and working from within. In these courses, formulas become inadequate, and more intellectual and ethical devotions have to be put forward (W. Ayers, personal communication, October 15, 2010). Yet, even such "reparation" work is slippery because it has to be bound by ethical choices and practices. Equally important, when we teachers encourage students to develop their intellectual and ethical endeavors, we cannot guarantee them with the right solution to multicultural education. We have to allow students to take detours, to doubt, to allow ourselves to pause, and to meet the "dilemmas of human condition."

This dilemma, or the pedagogical aporia, not only requires us to transform our minds to engage poetic and lived experiences of aporia, but also to engage Bodhisattva ethics, based upon compassion and wisdom. Thus we inform ourselves to mindfully live with the sufferings from both the students and ourselves, and transform our minds to welcome the impossibilities of teaching.

\section{Exploring Bodbisattva Compassion in Pedagogical Aporias}

Critical scholars have argued against the fixity of mechanical and instrumental pedagogy. This approach is vital for educators in multicultural and diversity education to unsettle social injustice and to bring about true democracy to all learners. Over the years I have been teaching at my college, I practiced a pedagogy that aimed at changing the mechanical and instrumental pedagogy. In the process, I have come to realize that as educators we could also become attached to our own fixity or dogma in attempts or efforts to undo fixity. My encounter and study with Buddhist practitioners and monastic community deepened my understandings of impermanence, emptiness, and compassion. My previous understandings of the "right" pedagogy were also unsettled, especially after I started meditation to observe the state of my mind. I become more and more aware of the struggles of my students and of my own - the pedagogical sufferings. The word suffering may seem problematic for some. However, as Wang (2005) argues, in avoiding conflict and not addressing suffering, we neglect our emotional wellbeing. Attending to the latter could be equally transformative and engaging as working with intellectual thoughts. Wang asks the pointed question: "How can we reach the ground of mutual - not common - understanding without addressing hurt, if we are to let go of our emotional attachment to the given?" (p. 58). She continues to point out: "Gary Howard argues that 'once suffering is acknowledged, it can be dealt with"” (quoted in Wang, 2005, pp. 58-59). Acknowledging suffering is one step away from mechanical and instrumental pedagogy, and it reminds us that both students and teachers are human beings, immersed in emotional and embodied interactions in learning.

Engaging Bodhisattva's ethics in pedagogical aporias requires us not only taking Buddhist compassion and wisdom as an intellectual understanding and knowing of the connotations and indications, but also we have to live through, emotionally engage with, and allow ourselves to be affected by compassion. A calmed, soft and compassionate heart benefits from patience and everyday cultivation. Pedagogy with compassion considers that suffering is something given in human life. We educators do not purposefully have to lead students into suffering so that they can learn from it. Rather, we just need to accept "suffering in place of all sentient beings" (Fa Zang, 1983, quoted in Fahy, 2012, p. 266). Suffering is a state that all sentient beings have to go through, and it cannot be eradicated in our life journey. The end of suffering is understood as Nirvana for the monastic community and rebirth in some better state of existence for the layman (Hamilton, 1950). In meeting suffering with Bodhisattva compassion, we patiently practice compassion and move beyond the initial states of emotion, and transform from 悲伤 (sorrow) to 悲心 (responsive heartmind). Without responsive heartmind, it is easier to be carried away by anger, silence, and resentment that students express, or our own sadness of not being able to teach the "right" thing. Immersed in sorrow, one remains in the passage of vijnana (consciousness), and is unable to see that our consciousness is conditioned by our knowledge of the "right" thing.

Although Bodhisattva ethics advocate self-perfection, the nature of Bodhisattva (not the Buddha) also indicates that a bodhisattva is on the way to perfection, and is never claimed as a perfected one. From the Bodhisattva's pedagogical perspective, all the difficulties, aporias, or unteachable moments are opportunities 
to refine our selves on the way to enlightenment. Instead of trying to get rid of these moments, we become mindful of their operations and representations, so as to come back with skillful and wholesome actions and engage them in new ways. If transforming the mind is to "transforms the environment to follow one's heartmind" (Heya, 2013, p. 189) with the skillful actions to perfect ourselves, indeed, what is transformed is not the environment itself, but our perceptions and consciousness of the environment. Considering the uncertainties in our daily pedagogical practices, we never fully know what experiences our students have gone through, and to what extent they relate their past experiences to our teaching at that moment. Thus, when such pedagogical aporias arise, we who have avowed to be teacherly Bodhisattvas find these moments as "perfect" for ourselves — teachers and students alike — in working toward pedagogical enlightenment.

\section{From Political to Ethical Pedagogy}

Usually multicultural education or any education relating to teaching social justice and social inequity involves a political attempt to change the world to a better place. In this process, out of the good intention to undo oppression, injustice, suffering, and struggles, we most often end up clinging to an assumed self-other relationship. In the field of curriculum studies, for example, William Pinar (2011) points out the centrality of the political, that is, of power in the field, and a strong sense of "I" that is exempted from its own critical examination. Thus, he calls for an ethical subject in curriculum studies that moves beyond the identity politics to engaging the question of "what knowledge is of most worth?" in our own ethical practices.

Bodhisattva ethics nurtured by compassion and wisdom provides us with both theoretical interpretations and practical guidance in developing ethical subjects. Informed by an ethics of compassion, I respond to the question of what knowledge is of most worth with the suggestion that we practice undifferentiated compassion in order to work with all sentient beings and encourage them to explore their own ethical knowledge and embodiment. Nurtured by wisdom, the pedagogy of compassion is a lived pedagogy toward both cognitive and embodied engagement with all sentient beings in or out of our classrooms.

\section{References}

Clark, A. (2011). Supersizing the mind: Embodiment, action, and cognitive extension. Oxford: Oxford University Press. Dupont, H. (1994). Emotional development, theory and applications: A neo-Piagetian perspective. Westport, CT: Praeger. Eppert, C. (2010). Heartmind literacy: Compassionate imagining and the four Brahmaviharas. Paideusis, 19(1), 17-28.

Fahy, G. (2012). Huayan Buddhism and Dewey: Emptiness, compassion, and the philosophical fallacy. Journal of Chinese Philosophy, 39(2), 260-271.

Garber, M. (2004). Compassion. In L. Berlant (Ed.), Compassion: The culture and politics of an emotion. New York: Routledge.

Inada, K. (2000). The nature of emptiness and Buddhist ethics. Chung-Hwa Buddhist Journal, 13(2), 255-275.

Hamilton, C. (1950). The idea of compassion in Mahayana Buddhism. Journal of the American Oriental Society, 70(3), 145-151.

Hayles, K. (2002). Flesh and metal: Reconfiguring the mindbody in virtual environments. Configurations, 10, 297-320.

Keith, N. (2010). Getting beyond anaemic love: From the pedagogy of cordial relations to a pedagogy for difference. Journal of Curriculum Studies, 42(4). 539-572.

Heya. (2013, May). 风动, 幡动, 心动? 佛光法苑 (Dharma Garden). 189, $22-24$.

King, S. (2006). An engaged Buddhist response to John Rawls's The law of peoples. Journal of Religious Ethics, 34(4), 637-661.

K. Sri Dhammananda (n.d.). What Buddhists believe. Houston: Texas Buddhist Association, Inc.

Lin, J. (2010). 林建德：论初期佛教 [识] 之概念及其特点 - 与现今主流学界意识 研究作对比 《揭谛》18(1), 1-44.

Piaget, J. (1981). Intelligence and affectivity: Their relationship during child development. Palo Alto, CA: Annual Reviews. 
Pinar, W. (2011). The character of curriculum studies: Bildung, currere, and the recurring questions of the subject. New York: Palgrave Macmillan.

Slattery, P. (2006). Curriculum development in the postmodern era (2nd ed.). New York: Routledge.

Sujiva (2009). <<慈心禅 >> [Loving-kindness meditation]. (S. Lei, Trans). Tai Bei: Oak Tree Publishing.

Tyler, R. (1949). Basic principles of curriculum and instruction. Chicago: University of Chicago Press.

Wang, H. (2005). Aporias, responsibility, and the im/possibility of teaching multicultural education. Educational Theory, 55(1), 45-59.

Wang, H. (2010, April). Unteachable moments and pedagogical relationships: A Kristevian lens. Paper presented at the American Educational Research Association (AERA) annual meeting, Denver, CO. Abstract retrieved from

http://convention2.allacademic.com/one/aera/aera10/index.php?click_key=1\&cmd=Multi+Search + Search+Load+Publication\&publication_id=383034\&PHPSESSID=2hjvp4ed97556iuh8u7tmpo9r2

Yao, F. (2008). The compatibility between bodhisattva compassion and 'no-self.' Asian Philosophy. 18(3), 267278.

\section{About the Author}

Dr. Mei Wu Hoyt is an Assistant Professor of Curriculum and Instruction in the Department of Teacher Education and Administration at the University of North Texas in Denton, Texas. Her research focuses on curriculum studies and digital learning, embodiment, and culture and education. Working within the intersections of cross-cultural and embodiment frameworks, Hoyt's recent research projects have involved mindfulness-based pedagogy, engaging compassion in teaching, and embodied learning with new technologies.

Email: mei.hoyt@unt.edu

Personal Website: http://www.interstanding.net 